\title{
Estrogen Stimulates a Transient Increase in the Number of New Neurons in the Dentate Gyrus of the Adult Female Rat
}

\author{
Patima Tanapat, Nicholas B. Hastings, Alison J. Reeves, and Elizabeth Gould \\ Department of Psychology, Princeton University, Princeton, New Jersey 08544
}

To determine whether a sex difference exists in the production of hippocampal cells during adulthood, we examined proliferating cells and their progeny in adult rats using the thymidine analog bromodeoxyuridine (BrdU) combined with immunohistochemistry for markers of neurons and glia. Additionally, to determine whether ovarian hormones affect cell proliferation, we examined the numbers of BrdU-labeled cells at different estrous cycle stages and after ovarian steroid manipulation. Stereological analyses of the numbers of BrdU-labeled cells revealed that females produced more cells than males in the dentate gyrus but not in the subventricular zone. The production of new hippocampal cells in females appears to be affected by ovarian hormone levels; ovariectomy diminished the number of BrdU-labeled cells, an effect reversed by estrogen replacement. A natural fluctuation in cell proliferation was also noted; females produced more cells during proestrus (when estrogen levels are highest) compared with estrus and diestrus. Many of

Granule neurons are produced in the dentate gyrus throughout life. In adulthood, precursor cells located in the hilus and subgranular zone $(\mathrm{sgz})$ of the dentate gyrus divide and produce daughter cells that ultimately differentiate into mature granule neurons (Altman and Das, 1965; Bayer, 1982; Cameron et al., 1993; Gould et al., 1997). Stereological analyses have demonstrated that thousands of new hippocampal granule cells are produced daily in adult rodents (Gould et al., 1999). Moreover, recent studies have demonstrated that this phenomenon also occurs in many different mammalian species (Gould et al., 1997, 1998, 1999a,b), including humans (Eriksson et al., 1998). The relatively high number of new neurons produced in adulthood and the conservation of this process across mammalian taxa suggest that these cells play an important role in hippocampal function.

Several previous studies have reported sex differences in hippocampal function. Specifically, sex differences have been observed in hippocampal long-term potentiation (Maren et al., 1994), as well as in the performance of various hippocampal-dependent tasks (Roof and Havens, 1992; Roof et al., 1993; Galea et al., 1996; Kavaliers et al., 1996). In addition, sex differences in hippocampal structure have been reported. With respect to the dentate gyrus, previous studies have demonstrated that males have a greater total number of granule neurons, as well as more mossy fiber synapses in the hilus than females (Madeira and Paula-Barbosa, 1993). Fe-

\footnotetext{
Received Feb. 22, 1999; revised April 19, 1999; accepted April 27, 1999.

This work was supported by National Institutes of Health Grants MH52423 and MH59740 (E.G.).

Correspondence should be addressed to Patima Tanapat, Department of Psychology, Princeton University, Green Hall, Princeton, NJ 08544.

Copyright (C) 1999 Society for Neuroscience $0270-6474 / 99 / 195792-10 \$ 05.00 / 0$
}

these cells acquired neuronal characteristics, including the formation of dendrites and expression of Turned-On-After-Division $64 \mathrm{kDa}$, a marker of immature granule neurons, and the calcium-binding protein calbindin, a marker of mature granule neurons. However, examination of the numbers of pyknotic cells and the numbers of BrdU-labeled cells at longer survival times revealed that many new cells in the dentate gyrus eventually degenerate. Consistently the number of labeled cells in females is no longer higher than that observed in males by 2 weeks after the last BrdU injection. These findings suggest that estrogen-enhanced cell proliferation during proestrus results in more immature neurons in the hippocampal formation of females compared with males and present the possibility that these new cells exert an important influence on hippocampal function.

Key words: neurogenesis; dentate gyrus; granule neuron; sex differences; estrous cycle; estrogen males, on the other hand, exhibit a greater number of mossy fiber synapses in the CA3 region (Madeira et al., 1991).

As in other brain regions, it is likely that many observed sex differences in hippocampal structure and function are dependent on the levels of circulating gonadal hormones during either development or adulthood (Arnold and Breedlove, 1985; McEwen et al., 1995). During development, estrogen treatment has been shown to affect the volume of the CA1 and CA3 regions, as well as spatial navigation behavior (Isgor and Sengelaub, 1998). Similarly, previous studies have demonstrated dramatic effects of the ovarian hormone estrogen during adulthood on the number of hippocampal synapses (Woolley and McEwen, 1992), the strength of hippocampal LTP (Cordoba Montoya and Carrer, 1997), and hippocampal-dependent learning (Daniel et al., 1997; Packard and Teather, 1997a,b; Luine et al., 1998). These findings raise the possibility that sex differences exist in adult neurogenesis in the dentate gyrus and furthermore that estrogen may play an important role.

To determine whether a sex difference exists in adult granule neuron production and survival, we examined proliferating cells and their progeny using the thymidine analog bromodeoxyuridine (BrdU) and immunohistochemistry for markers of neurons and glia, as well as the numbers of pyknotic cells, in adult male and female rats. In addition, to establish whether the production of new hippocampal cells is affected by changing levels of ovarian steroids in adulthood, we also characterized the production and survival of new hippocampal cells during different stages of the estrous cycle and after experimental manipulations of ovarian steroids. 


\section{MATERIALS AND METHODS}

Animal treatments. Adult male (320-350 gm) and female (200-280 gm) Sprague Dawley rats of the same age from the breeding colony at Princeton University were used in all experiments. The animals were group housed and maintained on a 12/12 hr light/dark cycle (lights on 7:00 A.M.), and provided with ad libitum access to food and water. In each experiment, stage of estrous was determined by examining vaginal cytology (Stockard and Papanicolaou, 1917; Shors et al., 1998) for a minimum of two weeks before treatment to insure that all female rats were cycling regularly. The rat estrous cycle lasts 4 or $5 \mathrm{~d}$ and consists of three stages: proestrus which lasts $12 \mathrm{hr}$, estrus which lasts $36 \mathrm{hr}$, and diestrus which may last either 48 or $72 \mathrm{hr}$ (Long and Evans, 1922). In general, $\sim 98 \%$ of the animals were judged to be cycling normally. For perfusion, all of the animals were deeply anesthetized with an overdose of sodium pentobarbital [Nembutal; $100 \mathrm{mg} / \mathrm{kg}$ body weight ( $\mathrm{b} \mathrm{wt}$ )] and then perfused transcardially with $4.0 \%$ paraformaldehyde in $0.1 \mathrm{M}$ phosphate buffer. All animal experimentation was conducted in accordance with University guidelines and with The National Institutes of Health Guide for the Care and Use of Laboratory Animals.

Experiment 1. To establish whether a sex difference exists in the number of adult-generated hippocampal cells, adult female and male rats were injected with $\mathrm{BrdU}(100 \mathrm{mg} / \mathrm{kg} \mathrm{b}$ wt, i.p.), a marker of proliferating cells and their progeny (Nowakowski et al., 1989), at 2:00 P.M. for 5 consecutive days. The animals were given daily injections for $5 \mathrm{~d}$ to eliminate potential variability caused by the stage of estrous of individual females at the time of injection. To insure that each female rat would experience the same amount of time in each stage of the estrous cycle during the injection period, only female rats that were in diestrus on the first day of injection were used. Groups of male and female rats $(n=$ 4-6) were then perfused either 2 or $14 \mathrm{~d}$ after the last injection. The brains were removed, post-fixed, and processed immunohistochemically for BrdU and BrdU combined with one of several markers including Turned-On-After-Division $64 \mathrm{kDa}$ (TOAD-64), a marker of immature neurons (Minturn et al., 1995); the calcium binding protein calbindin, a marker of mature granule neurons (Kempermann et al., 1997); and glial fibrillary acidic protein (GFAP), an astroglial marker (Cameron et al., 1993).

To determine whether potential sex differences in the numbers of proliferating cells may be attributable to sex differences in the numbers of progenitor cells in the adult dentate gyrus, adjacent sections were also processed for Ki67 immunohistochemistry. Ki67 is a protein that is expressed by cells throughout the cell cycle with the exception of a short period at the beginning of G1 (Lopez et al., 1991).

Experiment 2. To determine whether the proliferation of granule cell precursors and the production of new neurons are affected by estrous cycle stage, adult female rats in either proestrus, estrus, or diestrus were injected with $\mathrm{BrdU}(200 \mathrm{mg} / \mathrm{kg}$ b wt, i.p.) at 2:00 P.M. and perfused after a $2 \mathrm{hr}$ survival. For purposes of comparison, male rats were injected with $\mathrm{BrdU}$ and perfused $2 \mathrm{hr}$ later $(n=5-6)$. The $2 \mathrm{hr}$ survival was chosen because it is sufficient for the uptake of BrdU into proliferating cells but not for mitosis or migration to occur (Nowakowski et al., 1989). Additional female rats were injected with BrdU during either proestrus, a time of maximal estrogen levels, or estrus, a time of low estrogen levels, and subsequently perfused after the following survival times: 4, 7, 14, and $21 \mathrm{~d}(n=3)$. After perfusion, all of the brains were removed, post-fixed, and processed immunohistochemically for BrdU. In the case of animals that had a survival time $>2 \mathrm{hr}$, the brains were also processed for combined immunohistochemistry for BrdU and either TOAD-64, calbindin, or GFAP. Additionally, sections processed for BrdU staining alone were stained with cresyl violet for analysis of the numbers of pyknotic cells.

Experiment 3. To investigate the possibility that estrogen regulates the proliferation of granule cell precursors, adult female rats were anesthetized with Nembutal $(50 \mathrm{mg} / \mathrm{kg} \mathrm{b} \mathrm{wt})$ and either ovariectomized or sham ovariectomized. Six days after surgery, some of the ovariectomized rats were injected with $17-\beta$-estradiol in sesame oil vehicle $(10 \mu \mathrm{g} / \mathrm{rat}$, s.c.) while the remaining rats were injected with vehicle alone $(n=4-5)$. This dose was chosen because it results in circulating levels of estradiol (Viau and Meaney, 1991; Sohrabji et al., 1994) in the proestrus range. Two hours later, all of the rats were injected with $\operatorname{BrdU}(200 \mathrm{mg} / \mathrm{kg} \mathrm{b} \mathrm{wt}$, i.p.) and perfused after a $2 \mathrm{hr}$ survival. The brains were removed, post-fixed, and processed immunohistochemically for BrdU. The sections were then stained with cresyl violet for analysis of the numbers of pyknotic cells.

Histological procedures. For each brain, $40 \mu \mathrm{m}$ sections through the entire dentate gyrus were cut in a bath of $0.1 \mathrm{~m}$ PBS with an oscillating tissue slicer. Unless otherwise indicated, all washes and incubations were performed in PBS for peroxidase immunohistochemistry and in $0.1 \mathrm{M}$ Tris-buffered saline for fluorescence immunohistochemistry.

For peroxidase BrdU immunolabeling, the sections were incubated in $0.1 \mathrm{M}$ citric acid for $5 \mathrm{~min}$ at $90^{\circ} \mathrm{C}$, rinsed, incubated in $0.6 \% \mathrm{H}_{2} \mathrm{O}_{2}$ for 30 min, rinsed, digested in trypsin (0.001-0.05\%) in Tris buffer containing $0.1 \% \mathrm{CaCl}_{2}$ for $10 \mathrm{~min}$, rinsed, denatured in $2 \mathrm{~N} \mathrm{HCl}$ for $30 \mathrm{~min}$, rinsed (pH 6.0), blocked in 3.0\% normal horse serum for $30 \mathrm{~min}$, and incubated overnight at $4^{\circ} \mathrm{C}$ in mouse monoclonal antibody against BrdU $(1: 200+$ $0.5 \%$ Tween 20; Novocastra, Newcastle Upon Tyne, UK). On the next day, the sections were rinsed several times, incubated in biotinylated mouse secondary antisera (1:50; Vector Laboratories, Burlingame, CA) for $60 \mathrm{~min}$, rinsed, incubated in avidin-biotin-horseradish peroxidase (AB; 1:50; Vector Laboratories) for $60 \mathrm{~min}$, rinsed again, and reacted for 5 min in $0.02 \%$ diaminobenzidine (DAB) with $0.003 \% \mathrm{H}_{2} \mathrm{O}_{2}$ or in DAB containing $0.1 \%$ nickel ammonium sulfate and then rinsed. For combined labeling, sections were incubated in polyclonal antisera against one of the following: (1) rabbit anti-TOAD-64 (a gift from Dr. Susan Hockfield, 1:7500); (2) rabbit anti-calbindin (1:750 and 0.5\% Tween 20; Chemicon, Temecula, CA); or (3) goat anti-GFAP (1:5000; Santa Cruz Biotechnology, Santa Cruz, CA). On the following day, the sections were incubated in biotinylated secondary antisera for $60 \mathrm{~min}$, rinsed, incubated in $\mathrm{AB}$ for $60 \mathrm{~min}$, rinsed, and reacted in $\mathrm{DAB}$ for $5 \mathrm{~min}$. The sections were then mounted onto coated slides and dried, counterstained using cresyl violet, dehydrated, and coverslipped under Permount.

For fluorescence BrdU immunolabeling, sections were pretreated as above, incubated in primary antibody against BrdU overnight, rinsed, incubated in Cy3-conjugated mouse secondary antisera (1:200; Sigma, St. Louis, MO) for $15 \mathrm{~min}$, rinsed several times, and then incubated in polyclonal antisera against either TOAD-64, calbindin, or GFAP. On the next day, sections incubated in anti-TOAD-64 or anti-calbindin were incubated in Alexa 488-conjugated rabbit secondary antisera (1:1000; Molecular Probes, Eugene, OR) for $30 \mathrm{~min}$. Sections that were incubated in polyclonal antisera against GFAP were incubated in biotinylated secondary goat antisera for $60 \mathrm{~min}$, rinsed, and then incubated in Cy2conjugated avidin (1:1000; Amersham, Arlington Heights, IL) for 30 min. After rinsing, all of the sections were mounted, dried, and then coverslipped under $30 \%$ glycerol in TBS.

Additional sections processed for Ki67 peroxidase immunohistochemistry were incubated in $0.1 \mathrm{M}$ citric acid at $90^{\circ} \mathrm{C}$ for $5 \mathrm{~min}$, rinsed, and then incubated overnight in mouse monoclonal antisera against Ki67 (1:750; Novocastra). On the following day, the sections were rinsed, incubated in biotinylated mouse secondary antisera for $60 \mathrm{~min}$, rinsed, incubated in $\mathrm{AB}$ for $60 \mathrm{~min}$, rinsed and then reacted in $\mathrm{DAB}$ for $5 \mathrm{~min}$. The sections were mounted onto coated slides, dried, counterstained using cresyl violet, dehydrated, and coverslipped under Permount.

Data analysis. Prior to data analysis all of the slides were coded, and the code was not broken until the analysis was completed. Stereological estimates of the number of immunolabeled cells in the entire dentate gyrus were determined for brains processed for peroxidase BrdU or Ki67 immunolabeling and in the subventricular zone (svz) for brains processed for peroxidase $\mathrm{BrdU}$ immunolabeling. Because adult-generated cells that become neurons ultimately migrate out of the hilus, the numbers of BrdU-labeled cells in the hilus and sgz and gcl (combined) were initially examined separately for animals surviving longer than $2 \mathrm{hr}$ after BrdU injection. In addition, stereological estimates of the number of pyknotic cells in the $\operatorname{sgz}$ and $\mathrm{gcl}$ were also determined. Pyknotic cells were characterized by lack of nuclear membrane, pale or absent cytoplasm, and condensed, darkly stained spherical chromatin (Gould et al., 1991). The total number of pyknotic or immunolabeled cells was determined using a modified version of the optical fractionator method (West et al., 1991). All pyknotic or BrdU-labeled cells in the dentate gyrus were counted on every 12 th section throughout the dentate gyrus at $1000 \times$, omitting cells located in the outermost plane of focus, using an Olympus BX-60 light microscope attached to an Optronics color video camera and a Dell OptiPlex computer. For sections processed for combined immunohistochemistry, 4-6 anatomically matched sections from each brain were analyzed. The numbers of BrdU-labeled cells in the hilus and in the $\mathrm{gcl}$ and $\mathrm{sgz}$ (combined) that were immunoreactive or nonimmunoreactive for either TOAD-64, calbindin, or GFAP were then determined. Because BrdU-labeled cells in the hilus rarely express TOAD-64, calbindin, or GFAP (our unpublished observations), they are likely to primarily represent a progenitor population and were therefore analyzed for doublelabeling separately from those located in the gcl and sgz. A minimum of 
300-400 BrdU-labeled cells were analyzed per brain, and the numbers of double-labeled cells were expressed as percentages of the total number of BrdU-labeled cells in the respective regions. For fluorescence immunolabeling, tissue was examined first with a conventional fluorescence microscope (Olympus BX-60). Double-labeled cells were then verified using a confocal laser scanning microscope (Zeiss Axiovert 510 LSM). Z-sectioning at $1 \mu \mathrm{m}$ intervals was performed for analysis, and optical stacks of 5-6 images were produced for figures. Bilateral volume estimates of the gcl were made in experiments that compared the numbers of BrdU-labeled cells in male and female rats. These estimates were made by applying Cavalieri's Principle (Gundersen et al., 1988) to cross sectional area measurements of the gcl obtained via ImagePro software (Media Cybernetics). In addition, the optical fractionator method (West et al., 1991) was used to attain bilateral estimates of the total number of granule neurons in the dentate gyrus in experiments comparing males and females. An unbiased counting grid was superimposed on the video image of the section and granule cells in a $15 \times 15 \times 40 \mu \mathrm{m}$ sample volume were counted. Total cell counts were analyzed using one-way or two-way ANOVAs followed by Tukey-HSD post hoc comparisons. Cell percentages were analyzed using distribution-free methods; the KruskalWallis ANOVA by ranks followed by pairwise comparisons using the Mann-Whitney $U$ test.

\section{RESULTS}

\section{Sex differences in adult-generated cells in the dentate gyrus}

Female rats exhibited $\sim 45 \%$ more BrdU-labeled cells in the dentate gyrus compared with male rats $2 \mathrm{~d}$ after the last BrdU injection $\left(F_{(1,11)}=7.49 ; p=0.023\right)$ (Figs. $\left.1 A, 2 A, B\right)$. Whereas the numbers of BrdU-labeled cells in the $\mathrm{sgz}$ and gcl were higher in females, a sex difference in the numbers of BrdU-labeled cells in the hilus was not observed. In both males and females, the majority of BrdU-labeled cells were located in the gcl or sgz and expressed the morphological characteristics of granule cell precursors, i.e., medium-sized, round, or oval nuclei. The remaining BrdU-labeled cells had the morphological characteristics of glial precursors, i.e., small-sized, triangular or irregular-shaped cell bodies. Additionally, the percentage of BrdU-labeled cells that were immunoreactive for either TOAD-64, GFAP, or calbindin (Fig. 2C-E) did not differ between sexes. At this time point, $\sim 80 \%$ of BrdU-labeled cells in the gcl and $\mathrm{sgz}$ of males and females were immunoreactive for TOAD-64. These cells had the morphological characteristics of granule cells, i.e., a small amount of cytoplasm in the cell body and dendrites extending toward the molecular layer (Fig. $2 C$ ). In contrast, $<1 \%$ of BrdU-labeled cells were immunoreactive for calbindin, and $\sim 10 \%$ were immunoreactive for GFAP. In the hilus, no BrdU-labeled cells immunoreactive for either calbindin or TOAD-64 were observed and $<1 \%$ were immunoreactive for GFAP.

A sex difference in the numbers of BrdU-labeled cells was no longer evident by $14 \mathrm{~d}$ after the last BrdU injection (Fig. 1B). By this time point, the majority of the BrdU-labeled cells in both males and females were fully incorporated into the gcl and were morphologically identical to neighboring mature granule neurons. Additionally, the percentages of BrdU-labeled cells that were immunoreactive for calbindin or GFAP were similar in both groups. Approximately 50\% of BrdU-labeled cells in the gcl and sgz were immunoreactive for calbindin, whereas $\sim 10 \%$ were immunoreactive for GFAP. In the hilus, no BrdU-labeled cells immunoreactive for calbindin were detected, and $<1 \%$ of BrdUlabeled cells were immunoreactive for GFAP. The total volume of the gcl and the total numbers of granule neurons were not statistically different between males and females (Fig. 1C,D).

In addition, no sex differences in the numbers of Ki67-labeled cells in the dentate gyrus were observed $\left(F_{(1,4)}=1.39 ; p=0.301\right)$. In both males $(9448 \pm 561.5)$ and females $(10592 \pm 789.9)$,
Ki67-labeled cells were located in clusters primarily in the sgz (Fig. 2F) and exhibited the morphological characteristics and approximate distribution of BrdU-labeled cells $2 \mathrm{hr}$ after BrdU labeling (Fig. 2, compare $F$ to $J, K$ ).

\section{Estrous cycle effects on granule cell production in the adult dentate gyrus}

The total number of BrdU-incorporating cells observed in the dentate gyrus fluctuated across the estrous cycle. In animals perfused $2 \mathrm{hr}$ after BrdU injection, the numbers of BrdU-labeled cells in females that were injected during proestrus were $50 \%$ greater than those observed in female rats that were injected during either estrus or diestrus, as well as compared with those observed in age-matched males $\left(F_{(3,17)}=5.61 ; p=0.0073\right.$ ) (Fig. $3 A)$. Regardless of the stage of estrous at the time of BrdU injection, the majority of the BrdU-labeled cells were located in the sgz and expressed the morphological characteristics of granule cell precursors, whereas the remaining BrdU-labeled cells expressed the morphological characteristics of glial precursors. In contrast, no differences between either males and females, or females at any stage of the estrous cycle were detected in the numbers of BrdU-labeled cells in the $\operatorname{svz}\left(F_{(3,15)}=2.32 ; p=\right.$ $0.117)$. The total numbers of pyknotic cells observed in these animals were inversely correlated with the numbers of proliferating cells; that is, the numbers of pyknotic cells were $\sim 40 \%$ lower in females that were in proestrus on the day of perfusion compared with females that were in estrus or diestrus, and compared with age-matched males $\left(F_{(3,17)}=3.48 ; p=0.042\right)($ Fig. $3 B)$. No differences in the distribution of pyknotic cells were observed among groups. Pyknotic cells were located in the sgz and $\mathrm{gcl}$ and were characterized by the lack of a nuclear membrane, pale or absent cytoplasm, and condensed, darkly stained, spherical chromatin (Fig. 2L).

In female rats that were injected with BrdU during either estrus or proestrus, the total number of BrdU-labeled cells in the dentate gyrus increased between $2 \mathrm{hr}$ and $4 \mathrm{~d}$ after BrdU labeling. The total numbers of BrdU-labeled cells remained elevated up to $7 \mathrm{~d}$ after BrdU labeling and then gradually decreased $\left(F_{(3,15)}=\right.$ 13.7; $p=0.0001)$. The numbers of BrdU-labeled cells in females injected during proestrus remained higher than those observed in females injected during estrus until $14 \mathrm{~d}$ after BrdU labeling $\left(F_{(1,15)}=9.24 ; p=0.0083\right.$ ) (Fig. 4). By this time, many BrdUlabeled cells had become incorporated into the gcl, expressed the morphological characteristics of mature granule neurons, and expressed calbindin, a marker of mature granule neurons $(\sim 35 \%)$. By $21 \mathrm{~d}$, the majority of these cells were located deep in the $\mathrm{gcl}$ and were indistinguishable in morphology from neighboring granule cells. At this time point, the difference in the numbers of BrdU-labeled cells in females injected during either proestrus or estrus was no longer detectable. Although the numbers of BrdU-labeled cells in the sgz and gcl varied, no difference in the numbers of BrdU-labeled cells in the hilus was observed between females injected during proestrus or estrus, or at any time point.

The percentage of BrdU-labeled cells in all regions examined that were immunoreactive for TOAD-64, calbindin, or GFAP was similar between females injected during either proestrus or estrus (Table 1). In both groups, the percentage of BrdU-labeled cells in the $\mathrm{gcl}$ and $\mathrm{sgz}$ that were immunoreactive for calbindin demonstrated a gradual but steady increase from $2.5 \%$ at $4 \mathrm{~d}$ to $68 \%$ at $21 \mathrm{~d}(p=0.0003)$. In contrast, the percentages of BrdU-labeled cells in the $\mathrm{gcl}$ and $\mathrm{sgz}$ that were immunoreactive for either TOAD-64 $(\sim 60 \%)$ or GFAP $(\sim 15 \%)$ did not change significantly 
A 2 days following last BrdU injection

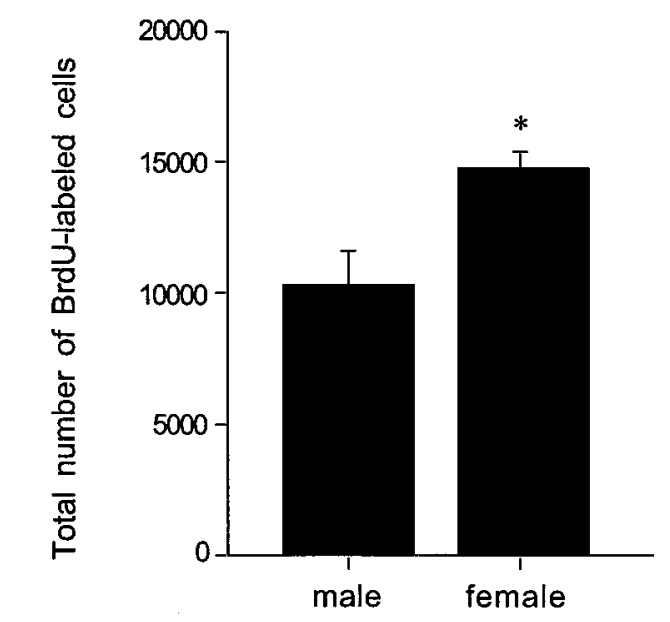

C

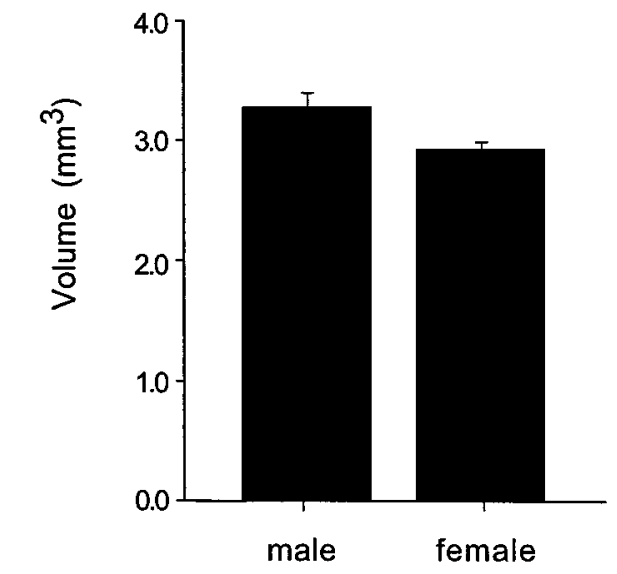

B 14 days following last BrdU injection

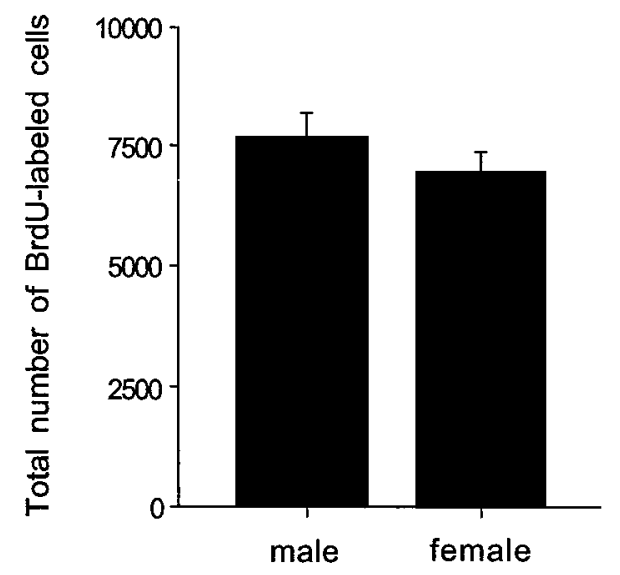

Total granule cell layer volume

Total number of granule neurons

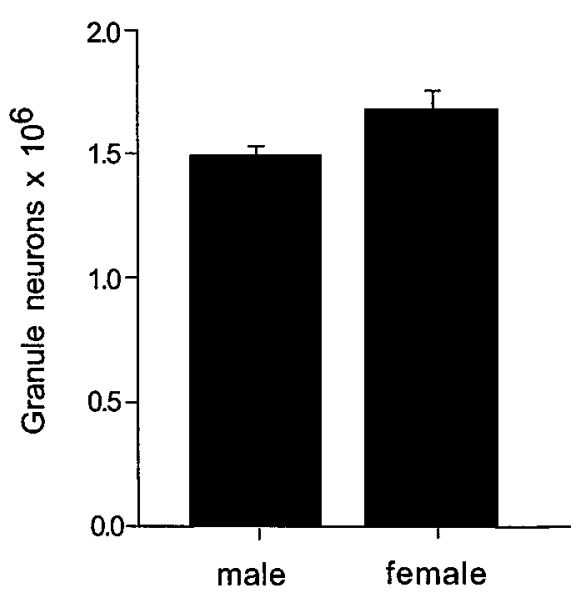

Figure 1. Stereological estimates of the total numbers of BrdU-labeled cells in the dentate gyrus of adult male and female rats. $A$, Two days after a period of five daily BrdU injections, female rats had significantly more BrdU-labeled cells in the dentate gyrus compared with age-matched males. $B$, By $14 \mathrm{~d}$ after the last BrdU injection, this sex difference was no longer evident. No significant differences in the granule cell layer volume $(C)$ or total number of granule neurons $(D)$ were observed between males and females. Bars represent mean + SEM, each obtained from four to six animals. Asterisk indicates a significant difference $(p<0.05)$.

over time in either group. Likewise, the percentages of doublelabeled cells did not change in the hilus. In females injected during proestrus or estrus, no BrdU-labeled cells immunoreactive for calbindin or TOAD-64 were detected at any time point in the hilus, and the percentage of BrdU labeled cells in the hilus that were immunoreactive for GFAP was consistently $<1 \%$.

\section{Estrogen effects on cell proliferation in the dentate gyrus of adult female rats}

Ovariectomy produced a $60 \%$ decrease in the numbers of BrdUlabeled cells in the dentate gyrus of adult female rats compared with those observed in both sham-operated animals (the majority of which were in proestrus on the day of BrdU injection), as well as those replaced with estrogen after ovariectomy $\left(F_{(2,12)}=24.23\right.$; $p=0.0001$ ) (Fig. 5A). Conversely, ovariectomized female rats demonstrated a twofold increase in the number of pyknotic cells in the gcl and sgz compared with those observed in shamoperated females or ovariectomized females that were replaced with estrogen $\left(F_{(2,17)}=24.04 ; p=0.0001\right)$ (Fig. $\left.5 B\right)$.

\section{DISCUSSION}

These findings demonstrate a sex difference in the production of new cells in the dentate gyrus resulting from a higher rate of cell proliferation in females during proestrus. The majority of new cells in males and females were located in the gcl or sgz, exhibited 

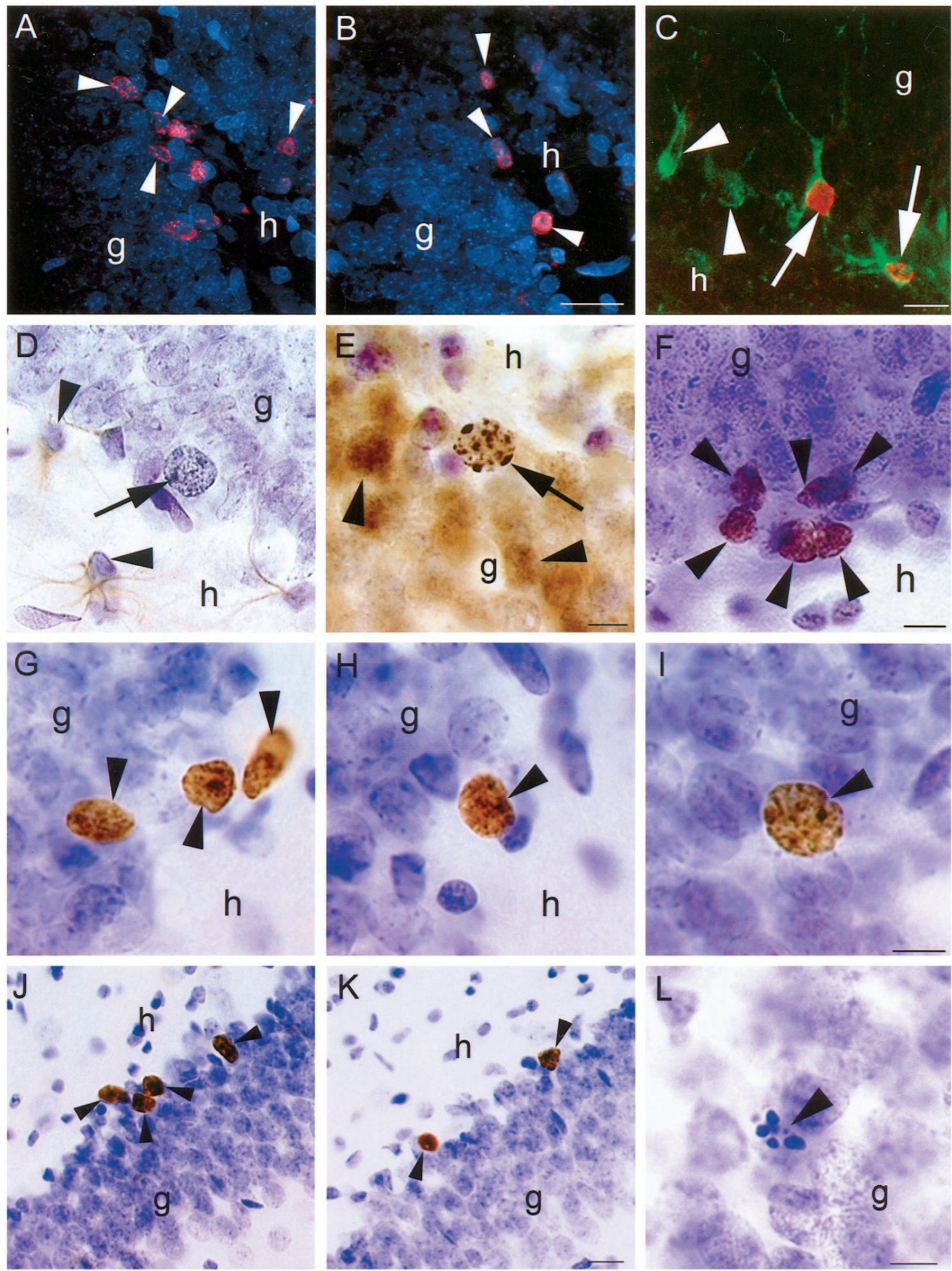

Figure 2. Confocal laser-scanning images of BrdU-labeled cells (arrowheads) in the dentate gyrus of female $(A)$ and male $(B)$ rats injected with BrdU five times and perfused $2 \mathrm{~d}$ after the last injection. More BrdU-labeled cells were observed in females compared with males. $C$, Confocal image of BrdU-labeled cells colabeled with TOAD-64, a marker of immature neurons (arrow), in the dentate gyrus of an adult female. Arrowheads indicate TOAD-64-labeled cells not labeled with BrdU. D, Light microscopic image of a BrdU-labeled cell (arrow) that is not colabeled with GFAP, a marker of astroglia, in the dentate gyrus of an adult female. Arrowheads indicate GFAP-labeled cells not labeled with BrdU. E, BrdU-labeled cell (arrow) that is colabeled with calbindin, a marker of mature neurons, in the dentate gyrus of an adult female. Arrowheads indicate calbindin-labeled cells not labeled with BrdU. F, Ki67-labeled cells (arrowheads) in the subgranular zone of the dentate gyrus. These cells were similar in morphology and location to BrdU-labeled cells at early time points. BrdU-labeled cells (arrowheads) at $4 \mathrm{~d}(G), 7 \mathrm{~d}(H)$, and $21 \mathrm{~d}(I)$ after BrdU injection in the dentate gyrus of the adult female. With increasing time after BrdU injection, many BrdU-labeled cells become incorporated into the granule cell layer and express the morphological characteristics of mature granule neurons. More BrdU-labeled cells (arrowheads) were observed in animals injected during proestrus $(J)$ compared with those injected during estrus $(K)$. These animals were perfused $2 \mathrm{hr}$ after injection with BrdU. $L$, Pyknotic cell (arrowhead) in the dentate gyrus of an adult female. These cells were more numerous in females than males during the majority of the estrous cycle, $g$, Granule cell layer; $h$, hilus. Scale bars: $B, 25 \mu \mathrm{m}$ (applies to $A, B$ ); $C, 10 \mu \mathrm{m} ; E, 10 \mu \mathrm{m}$ (applies to $D, E$ ); $F, 10 \mu \mathrm{m} ; I, 10 \mu \mathrm{m}$ (applies to G-I); $K, 25 \mu \mathrm{m}$ (applies to $J, K$ ); $L, 10 \mu \mathrm{m}$. 
A

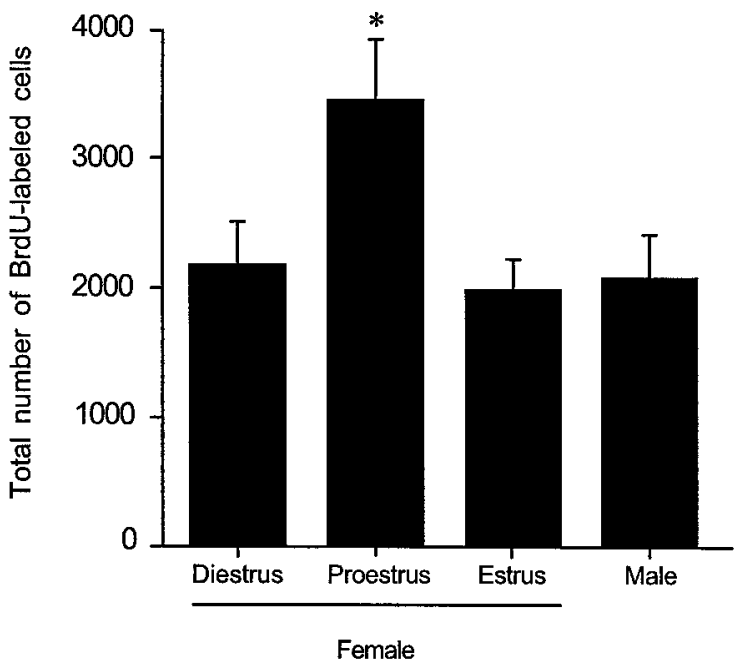

B

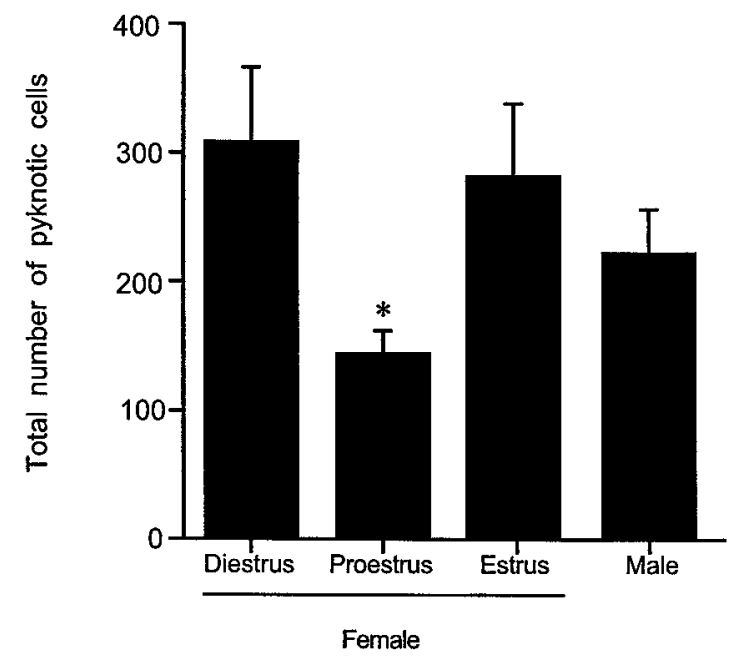

Figure 3. Stereological estimates of the total number of BrdU-labeled cells in the dentate gyrus $(A)$ and pyknotic cells in the sgz $(B)$ of adult female rats injected with BrdU during diestrus, proestrus, or estrus and in age-matched male rats. All animals were perfused $2 \mathrm{hr}$ after BrdU injection. Female rats injected during proestrus had significantly more BrdU-labeled cells compared with females in estrus or diestrus, as well as compared with age-matched males. Conversely, female rats in proestrus on the day of perfusion had significantly fewer pyknotic cells compared with females in estrus or diestrus, as well as compared with age-matched males. Bars represent mean + SEM each obtained from five or six animals. Asterisk indicates a significant difference from all other means $(p<0.05)$.

morphological characteristics of granule neurons, and expressed a marker of immature granule neurons (TOAD-64) but not a marker of astroglia (GFAP). However, our results indicate that under standard laboratory conditions, a greater number of cells degenerate in females than in males. This conclusion is consistent with our observations that (1) a sex difference in the number of BrdU-labeled cells was no longer detectable 2 weeks after BrdU injection; (2) females exhibited more pyknotic cells in the sgz and gcl compared with males during the majority of the estrous cycle;

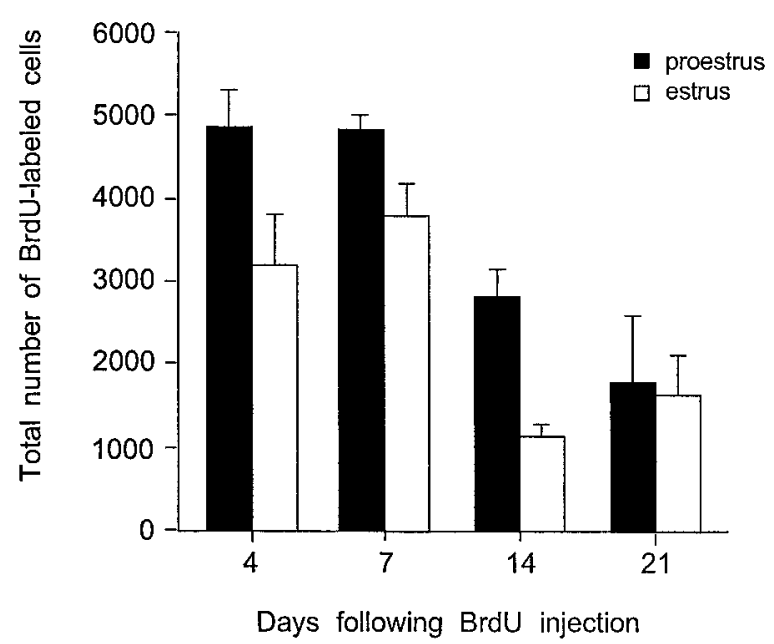

Figure 4. Stereological estimates of the total number of BrdU-labeled cells in the dentate gyrus of adult female rats $4,7,14$, and $21 \mathrm{~d}$ after a single BrdU injection administered during proestrus (black bars) or estrus (white bars). The numbers of BrdU-labeled cells decreased over time in both groups but were greater in females injected during proestrus up to $14 \mathrm{~d}$ after BrdU labeling. By $21 \mathrm{~d}$, this difference was no longer detectable. Bars represent mean + SEM each obtained from three animals. Asterisk indicates significant difference from proestrus $(p<0.05)$. and (3) there was no sex difference in the total number of granule neurons in the dentate gyrus.

Our results demonstrate a positive correlation between circulating estrogen levels and cell proliferation across the estrous cycle, and after experimental hormone manipulation. Conversely, we observed a negative correlation between circulating estrogen levels and the numbers of pyknotic cells. This suggests that estrogen not only stimulates cell proliferation, but also exerts important survival effects, a finding consistent with results of studies in avian systems (Burek et al., 1995; Hidalgo et al., 1995). Although the population of cells that degenerates in response to decreased estrogen levels is undetermined, the presence of pyknotic cells in the sgz suggests that some of these cells are new neurons.

The total number of new cells produced when estrogen was high (proestrus) compared with when estrogen was low (estrus) remained elevated until $14 \mathrm{~d}$ after BrdU labeling. At this time, many new cells generated during estrus or proestrus expressed a marker of mature granule neurons (calbindin) and were morphologically indistinguishable from neighboring granule cells. However, a difference in the number of new neurons produced during proestrus versus estrus was not detectable $21 \mathrm{~d}$ after labeling, presumably as a result of cell death. Collectively, our observations indicate that proestrus-associated increases in estrogen stimulate cell proliferation, which produces a transient increase in the pool of new neurons in the dentate gyrus. Given that new cells extend axons into the CA3 region 4-10 d after BrdU incorporation (Hastings and Gould, 1999), these cells may have a functional impact, even at an immature stage. Thus, sex differences in immature neuron production may have a significant implications for hippocampal structure and function.

Sex differences in hippocampal structure and function Several studies have reported sex differences in hippocampal structure, including a sex difference in the pattern of mossy fiber 
Table 1. Percentages of BrdU-labeled cells immunoreactive for calbindin, TOAD-64, or GFAP in the dentate gyrus of adult female rats at 4, 7, 14, and $21 \mathrm{~d}$ after BrdU injection

\begin{tabular}{|c|c|c|c|c|c|c|}
\hline \multirow[b]{2}{*}{ Days } & \multicolumn{2}{|l|}{ Calbindin } & \multicolumn{2}{|l|}{ TOAD-64 } & \multicolumn{2}{|l|}{ GFAP } \\
\hline & $\mathrm{gcl}$ and $\mathrm{sgz}$ & Hilus & $\mathrm{gcl}$ and $\mathrm{sgz}$ & Hilus & gcl and sgz & Hilus \\
\hline 4 & $2.5 \pm 1.84 \%$ & None & $60.4 \pm 6.53 \%$ & None & $14.8 \pm 2.19 \%$ & $<1.0 \%$ \\
\hline 7 & $10.3 \pm 3.51 \%$ & None & $73.1 \pm 2.02 \%$ & None & $13.8 \pm 2.44 \%$ & $<1.0 \%$ \\
\hline 14 & $34.2 \pm 8.17 \%$ & None & $53.3 \pm 9.43 \%$ & None & $17.0 \pm 2.61 \%$ & $<1.0 \%$ \\
\hline 21 & $68.3 \pm 12.05 \%$ & None & $51.8 \pm 12.89 \%$ & None & $22.6 \pm 3.94 \%$ & $<1.0 \%$ \\
\hline
\end{tabular}

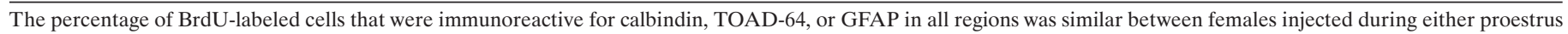

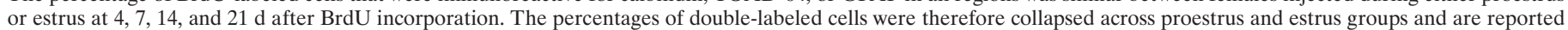

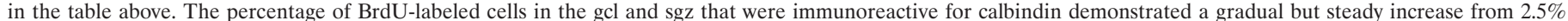

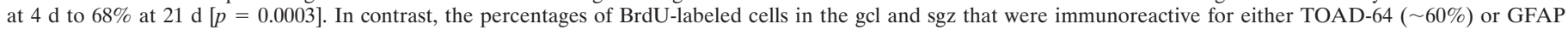

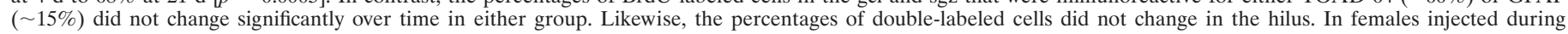

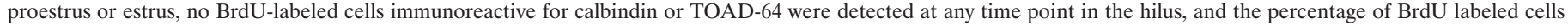
in the hilus that were immunoreactive for GFAP was consistently $<1.0 \%$.

A

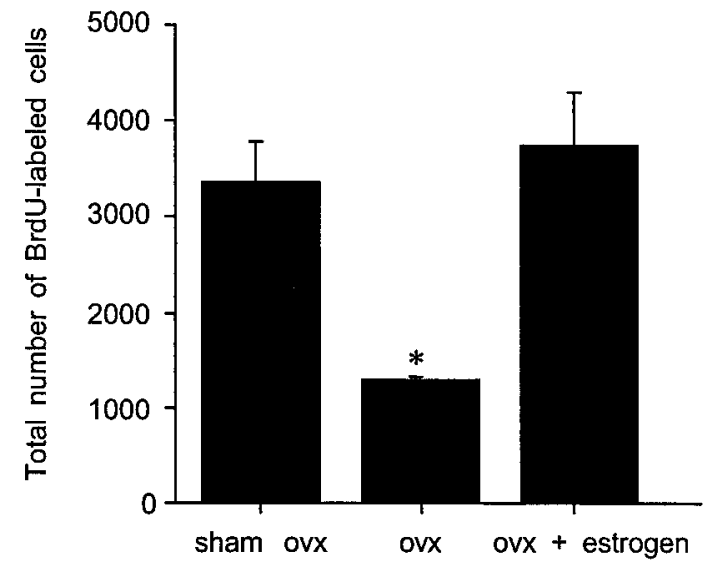

B

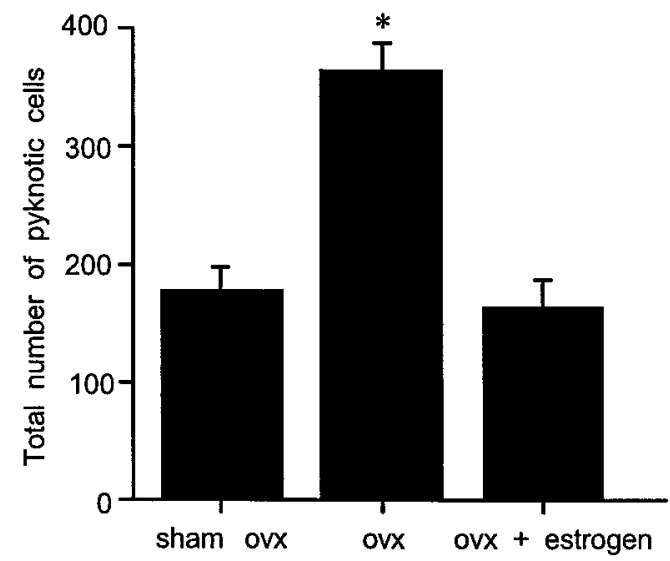

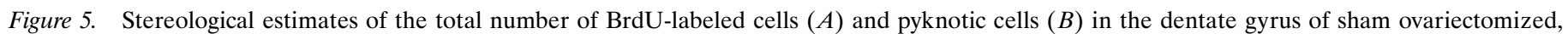

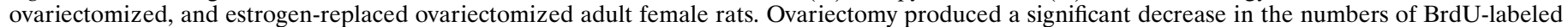

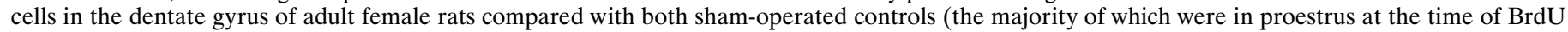

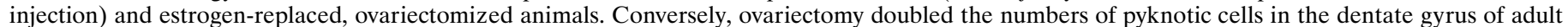

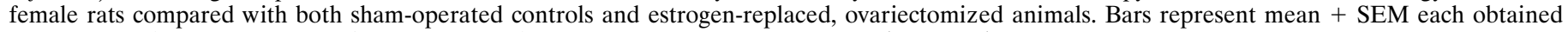
from four or five animals. Asterisk indicates significant difference from other means $(p<0.05)$.

innervation. Although the overall number of mossy fiber synapses does not differ, male rats have more mossy fiber synapses in the hilus (Parducz and Garcia-Segura, 1993), whereas females have more mossy fiber synapses in the CA3 region (Madeira et al., 1991). Previous studies have suggested that developmentally younger granule cells have more restricted projection patterns (Gaarskjaer, 1985). Thus, differences in granule cell production during adulthood may account for sex differences in mossy fiber distribution. Although we found a sex difference favoring females in adult granule cell production, we did not observe sex differences in total granule cell number or gcl volume. These findings differ from a previous report of more granule neurons and larger gcl volume in males compared with females (Madeira and PaulaBarbosa, 1993). This discrepancy may be caused by age differences (the rats examined in our study were younger) and different methods of determining cell number. We used the fractionator method, a stereological method not confounded by volumetric differences between groups, whereas the previous study used a method that involves multiplying numerical density by gcl volume of two separate sets of animals.

Numerous studies have demonstrated sex differences in hip- pocampal-dependent function and specifically, in hippocampaldependent learning. In general, these studies report augmented learning in males compared with females. For example, it has been shown that males perform better than females on the Morris water maze spatial task in several rodent species, including deer mice (Kavaliers et al., 1996), voles (Galea et al., 1996), and rats [although conflicting reports exist concerning rats (Roof and Havens, 1992; Roof et al., 1993; Bucci et al., 1995)]. However, a recent study has demonstrated that the sex difference in rats favoring males in spatial learning on this task can be reversed with previous familiarization to the testing apparatus (Perrot-Sinal et al., 1996). Females learn spatial tasks better than males once the novelty of the task is removed. Similarly, another paradigm less prone to performance confounds has also found a sex difference favoring females in hippocampal-dependent learning. This study reported that females learn trace eyeblink conditioning, a classical conditioning paradigm that requires the hippocampus for acquisition, faster than males (Wood et al., 1998). At present, the extent to which these sex differences in hippocampal-dependent behaviors are related to sex differences in adult cell production remains unknown. 


\section{Estrogen effects on hippocampal structure and function}

Our findings demonstrate a novel effect of estrogen on the adult hippocampal formation, the stimulation of new cell production. This effect appears to be mediated by circulating estrogen levels during adulthood; estrogen removal during adulthood decreased cell proliferation, whereas estrogen treatment rapidly reversed this effect. Additionally, no sex difference in the numbers of Ki67-labeled cells was detected, suggesting that estrogen-induced changes in cell proliferation did not result from differences in precursor cell number.

In other non-neuronal systems, estrogen has been shown to stimulate mitosis (Watters et al., 1997; Lee and Eghbali-Webb, 1998), possibly by regulation of the G1/S transition of the cell cycle (Geum et al., 1997; Hong et al., 1998). The magnitude and speed of observed increases in cell proliferation in the dentate gyrus suggest that estrogen may disinhibit a population of precursor cells that are normally prevented from progressing through the cell cycle at the G1/S transition. Alternatively, estrogen may stimulate precursor cells to divide at a faster rate by shortening G1.

Numerous studies have focused on ovarian steroid effects on hippocampal structure and function in adulthood. Several of these have demonstrated a positive correlation between estrogen and dendritic spine and synapse density in the hippocampal CA1 region after experimental manipulations and in response to natural fluctuations (Woolley et al., 1990; Woolley and McEwen, 1992; Desmond and Levy, 1997). These observations have prompted studies designed to investigate how differences in hippocampal physiology associated with the estrous cycle, or with estrogen treatment, affect performance of hippocampaldependent tasks. Although estrogen treatment has generally been found to enhance learning (Daniel et al., 1997; Packard and Teather, 1997a,b; Luine et al., 1998; Packard, 1998), the results of estrous cycle studies have been conflicting (Warren et al., 1995; Stackman et al., 1997; Warren and Juraska, 1997), most likely because of differences in estrous stage performance and the tasks examined.

With regard to how the present findings relate to hippocampaldependent learning, it is important to note that estrogen-induced changes in cell proliferation are unlikely to result in immediate changes in hippocampal function. Because new cells require time to become integrated into existing circuitry, the period after changes in cell proliferation is likely to be the most functionally relevant. Additionally, estrogen-induced stimulation of cell proliferation is likely to have important functional consequences when estrogen levels are elevated or diminished chronically, as during pregnancy or with aging.

In previous work, we have demonstrated that adrenal steroids inhibit granule cell proliferation in male rats (Gould et al., 1992; Cameron and Gould, 1994). Likewise, we have shown that stressful experiences, which increase circulating levels of glucocorticoids, also suppress cell proliferation, and ultimately, the production of new granule neurons (Gould et al., 1997, 1998). Given that the hypothalamic-pituitary-adrenal (HPA) axis is known to suppress gonadal steroid levels (Kamel and Kubajak, 1987; Rabin et al., 1988; Laatikainen, 1991), the impact of estrogen-induced changes in cell proliferation is likely to be complicated by interactions with glucocorticoids. Moreover, numerous studies have demonstrated sex differences in the HPA axis (Handa et al., 1994; Chisari et al., 1995) and in the effects of stress (Kavaliers and
Galea, 1995; Wood et al., 1998), which are also likely to impact estrogen effects on cell proliferation.

\section{Functional significance of adult-generated hippocampal neurons}

The functional significance of granule neurons produced in adulthood remains enigmatic. Recent studies have demonstrated that a substantial number of new neurons are produced in adulthood in many mammals (Cameron et al., 1993; Gould et al., 1997, 1998, 1999a,b), including humans (Eriksson et al., 1998). Additionally, our observations that new cells extend axons 4-10 d after mitosis (Hastings and Gould, 1999) suggest that they may be rapidly integrated into functional circuitry and thus, may play an important role in hippocampal function.

The hippocampal formation has been implicated in certain types of learning and memory. One theory proposes that the hippocampal formation plays a transient role in memory storage (Squire and Zola, 1998). If the hippocampal formation is necessary for temporary processing of information that is sent elsewhere for storage, then a rejuvenating population of neurons capable of rapidly forming synaptic connections may be well suited to participate in such a function, a possibility previously suggested for the bird song system (Nottebohm, 1989). Further evidence for a possible role of adult-generated cells in learning comes from studies of birds and mice demonstrating that environmental complexity enhances the number of adult-generated hippocampal neurons (Barnea and Nottebohm, 1994; Kempermann et al., 1997). Our recent results have shown that hippocampal-dependent learning increases the number of new granule neurons by enhancing their survival, suggesting an important association between learning and adult-generated neurons (Gould et al., 1999a). Comparisons between sexes have not been performed for either enriched environment or learning effects on new neurons. The results of the present report demonstrating that females produced more new cells that acquire characteristics of immature neurons than males, but that many of these cells die in deprived laboratory conditions, present the intriguing possibility that conditions of enhanced environmental complexity and increased learning opportunities may have a greater impact on the hippocampal structure in females than in males.

\section{REFERENCES}

Altman J, Das GD (1965) Autoradiographic and histological evidence of postnatal hippocampal neurogenesis in rats. J Comp Neurol 124:319-335.

Arnold AP, Breedlove SM (1985) Organizational and activational effects of sex steroids on brain and behavior: a reanalysis. Horm Behav 19:469-498.

Barnea A, Nottebohm F (1994) Seasonal recruitment of hippocampal neurons in adult free-ranging black-capped chickadees. Proc Natl Acad Sci USA 91:11217-11221.

Bayer SA (1982) Changes in the total number of dentate granule cells in juvenile and adult rats: a correlated volumetric and $3 \mathrm{H}$-thymidine autoradiographic study. Exp Brain Res 46:315-323.

Bucci DJ, Chiba AA, Gallagher M (1995) Spatial learning in male and female Long-Evans rats. Behav Neurosci 109:180-183.

Burek MJ, Nordeen KW, Nordeen EJ (1995) Estrogen promotes neuron addition to an avian song-control nucleus by regulating post-mitotic events. Brain Res Dev Brain Res 85:220-224.

Cameron HA, Gould E (1994) Adult neurogenesis is regulated by adrenal steroids in the dentate gyrus. Neuroscience 61:203-209.

Cameron HA, Woolley CS, McEwen BS, Gould E (1993) Differentiation of newly born neurons and glia in the dentate gyrus of the adult rat. Neuroscience 56:337-344. 
Chisari A, Carino M, Perone M, Gaillard RC, Spinedi E (1995) Sex and strain variability in the rat hypothalamo-pituitary-adrenal (HPA) axis function. J Endocrinol Invest 18:25-33.

Cordoba Montoya DA, Carrer HF (1997) Estrogen facilitates induction of long term potentiation in the hippocampus of awake rats. Brain Res 778:430-438.

Daniel JM, Fader AJ, Spencer AL, Dohanich GP (1997) Estrogen enhances performance of female rats during acquisition of a radial arm maze. Horm Behav 32:217-225.

Desmond NL, Levy WB (1997) Ovarian steroidal control of connectivity in the female hippocampus: an overview of recent experimental findings and speculations on its functional consequences. Hippocampus 7:239-245.

Eriksson PS, Perfilieva E, Bjork-Eriksson T, Alborn AM, Nordborg C, Peterson DA, Gage FH (1998) Neurogenesis in the adult human hippocampus. Nat Med 4:1313-1317.

Gaarskjaer FB (1985) The development of the dentate area and the hippocampal mossy fiber projection of the rat. J Comp Neurol 241:154-170.

Galea LA, Kavaliers M, Ossenkopp KP (1996) Sexually dimorphic spatial learning in meadow voles Microtus pennsylvanicus and deer mice Peromyscus maniculatus. J Exp Biol 199:195-200.

Geum D, Sun W, Paik SK, Lee CC, Kim K (1997) Estrogen-induced cyclin D1 and D3 gene expressions during mouse uterine cell proliferation in vivo: differential induction mechanism of cyclin D1 and D3. Mol Reprod Dev 46:450-458.

Gould E, Woolley CS, McEwen BS (1991) Naturally occurring cell death in the developing dentate gyrus of the rat. J Comp Neurol 304:408-418.

Gould E, Cameron HA, Daniels DC, Woolley CS, McEwen BS (1992) Adrenal hormones suppress cell division in the adult rat dentate gyrus. J Neurosci 12:3642-3650.

Gould E, McEwen BS, Tanapat P, Galea LAM, Fuchs E (1997) Neurogenesis in the dentate gyrus of the adult tree shrew is regulated by psychosocial stress and NMDA receptor activation. J Neurosci 17:2492-2498.

Gould E, Tanapat P, McEwen BS, Flugge G, Fuchs E (1998) Proliferation of granule cell precursors in the dentate gyrus of adult monkeys is diminished by stress. Proc Natl Acad Sci USA 95:3168-3171.

Gould E, Beylin A, Tanapat P, Reeves AJ, Shors TJ (1999a) Learning enhances adult neurogenesis in the hippocampal formation. Nat Neurosci 2:260-265.

Gould E, Reeves AJ, Fallah M, Tanapat P, Gross CG, Fuchs E (1999b) Hippocampal neurogenesis in adult old world primates. Proc Natl Acad Sci USA 96:5263-5267.

Gundersen HJ, Bagger P, Bendtsen TF, Evans SM, Korbo L, Marcussen N, Moller A, Nielsen K, Nyengaard JR, Pakkenberg B (1988) The new stereological tools: disector, fractionator, nucleator and point sampled intercepts and their use in pathological research and diagnosis. APMIS 96:857-881.

Handa RJ, Burgess LH, Kerr JE, O'Keefe JA (1994) Gonadal steroid hormone receptors and sex differences in the hypothalamo-pituitaryadrenal axis. Horm Behav 28:464-476.

Hastings NB, Gould E (1999) Adult-generated granule cells rapidly extend axons into the $\mathrm{CA} 3$ region: a combined BrdU-labeling and retrograde tracer study. J Comp Neurol, in press.

Hidalgo A, Barami K, Iversen K, Goldman SA (1995) Estrogens and non-estrogenic ovarian influences combine to promote the recruitment and decrease the turnover of new neurons in the adult female canary brain. J Neurobiol 27:470-487.

Hong J, Shah NN, Thomas TJ, Gallo MA, Yurkow EJ, Thomas T (1998) Differential effects of estradiol and its analogs on cyclin D1 and CDK4 expression in estrogen receptor positive MCF-7 and estrogen receptortransfected MCF-10AEwt5 cells. Oncol Rep 5:1025-1033.

Isgor C, Sengelaub DR (1998) Prenatal gonadal steroids affect adult spatial behavior, CA1 and CA3 pyramidal cell morphology in rats. Horm Behav 34:183-198.

Kamel F, Kubajak CL (1987) Modulation of gonadotropin secretion by corticosterone: interaction with gonadal steroids and mechanism of action. Endocrinology 121:561-568.

Kavaliers M, Galea LA (1995) Sex differences in the expression and antagonism of swim stress-induced analgesia in deer mice vary with the breeding season. Pain 63:327-334.

Kavaliers M, Ossenkopp KP, Prato FS, Innes DG, Galea LA, Kinsella DM, Perrot-Sinal TS (1996) Spatial learning in deer mice: sex differ- ences and the effects of endogenous opioids and $60 \mathrm{~Hz}$ magnetic fields. J Comp Physiol 179:715-724.

Kempermann G, Kuhn HG, Gage FH (1997) More hippocampal neurons in adult mice living in an enriched environment. Nature 386:493-495.

Laatikainen TJ (1991) Corticotropin-releasing hormone and opioid peptides in reproduction and stress. Ann Med 23:489-496.

Lee HW, Eghbali-Webb M (1998) Estrogen enhances proliferative capacity of cardiac fibroblasts by estrogen receptor- and mitogenactivated protein kinase-dependent pathways. J Mol Cell Cardiol 30:1359-1368.

Long JA, Evans HM (1922) The oestrus cycle in the rat and its associated phenomena. Mem Univ California 6:1.

Lopez F, Belloc F, Lacombe F, Dumain P, Reiffers J, Bernard P, Boisseau MR (1991) Modalities of synthesis of Ki67 antigen during the stimulation of lymphocytes. Cytometry 12:42-49.

Luine VN, Richards ST, Wu VY, Beck KD (1998) Estradiol enhances learning and memory in a spatial memory task and effects levels of monoaminergic neurotransmitters. Horm Behav 34:149-162.

Madeira MD, Paula-Barbosa MM (1993) Reorganization of mossy fiber synapses in male and female hypothyroid rats: a stereological study. J Comp Neurol 337:334-352.

Madeira MD, Sousa N, Paula-Barbosa MM (1991) Sexual dimorphism in the mossy fiber synapses of the rat hippocampus. Exp Brain Res 87:537-545.

Maren S, De Oca B, Fanselow MS (1994) Sex differences in hippocampal long-term potentiation (LTP) and Pavlovian fear conditioning in rats: positive correlation between LTP and contextual learning. Brain Res 661:25-34.

McEwen BS, Gould E, Orchinik M, Weiland NG, Woolley CS (1995) Oestrogens and the structural and functional plasticity of neurons: implications for memory, ageing and neurodegenerative processes. Ciba Found Symp 191:52-66.

Minturn JE, Geschwind DH, Fryer HJ, Hockfield S (1995) Early postmitotic neurons transiently express TOAD-64, a neural specific protein. J Comp Neurol 355:369-379.

Nottebohm F (1989) Hormonal regulation of synapses and cell number in the adult canary brain and its relevance to theories of long-term memory storage. In: Neural control of reproductive function (Lakoski J, Perez-Polo JR, Rossin D, eds), pp 583-601. Alan R. Liss.

Nowakowski RS, Lewin SB, Miller MW (1989) Bromodeoxyuridine immunohistochemical determination of the lengths of the cell cycle and the DNA-synthetic phase for an anatomically defined population. J Neurocytol 18:311-318.

Packard MG (1998) Posttraining estrogen and memory modulation. Horm Behav 34:126-139.

Packard MG, Teather LA (1997a) Posttraining estradiol injections enhance memory in ovariectomized rats: cholinergic blockade and synergism. Neurobiol Learn Mem 68:172-188.

Packard MG, Teather LA (1997b) Intra-hippocampal estradiol infusion enhances memory in ovariectomized rats. NeuroReport 8:3009-3013.

Parducz A, Garcia-Segura LM (1993) Sexual differences in the synaptic connectivity in the rat dentate gyrus. Neurosci Lett 161:53-56.

Perrot-Sinal TS, Kostenuik MA, Ossenkopp KP, Kavaliers M (1996) Sex differences in performance in the Morris water maze and the effects of initial nonstationary hidden platform training. Behav Neurosci 110:1309-1320.

Rabin D, Gold PW, Margioris AN, Chrousos GP (1988) Stress and reproduction: physiologic and pathophysiologic interactions between the stress and reproductive axes. Adv Exp Med Biol 245:377-387.

Roof RL, Havens MD (1992) Testosterone improves maze performance and induces development of a male hippocampus in females. Brain Res 572:310-313.

Roof RL, Zhang Q, Glasier MM, Stein DG (1993) Gender-specific impairment on Morris water maze task after entorhinal cortex lesion. Behav Brain Res 57:47-51.

Shors TJ, Lewczyk C, Pacynski M, Mathew PR, Pickett J (1998) Stages of estrous mediate the stress-induced impairment of associative learning in the female rat. NeuroReport 9:419-423.

Sohrabji F, Miranda RC, Toran-Allerand CD (1994) Estrogen differentially regulates estrogen and nerve growth factor receptor mRNAs in adult sensory neurons. J Neurosci 14:459-471.

Squire LR, Zola SM (1998) Episodic memory, semantic memory, and amnesia. Hippocampus 8:205-211. 
Stackman RW, Blasberg ME, Langan CJ, Clark AS (1997) Stability of spatial working memory across the estrous cycle of Long-Evans rats. Neurobiol Learn Mem 67:167-171.

Stockard CR, Papanicolaou GN (1917) The existence of a typical oestrous cycle in the guinea-pig with a study of its histological and physiological changes. Am J Anat 22:225.

Viau V, Meaney MJ (1991) Variations in the hypothalamic-pituitaryadrenal response to stress during the estrous cycle in the rat. Endocrinology 129:2503-2511.

Warren SG, Juraska JM (1997) Spatial and nonspatial learning across the rat estrous cycle. Behav Neurosci 111:259-266.

Warren SG, Humphreys AG, Juraska JM, Greenough WT (1995) LTP varies across the estrous cycle: enhanced synaptic plasticity in proestrus rats. Brain Res 703:26-30.

Watters JJ, Campbell JS, Cunningham MJ, Krebs EG, Dorsa DM (1997)
Rapid membrane effects of steroids in neuroblastoma cells: effects of estrogen on mitogen activated protein kinase signalling cascade and c-fos immediate early gene transcription. Endocrinology 138:4030-4033.

West MJ, Slomianka L, Gundersen HJ (1991) Unbiased stereological estimation of the total number of neurons in the subdivisions of the rat hippocampus using the optical fractionator. Anat Rec 231:482-497.

Wood GE, Beylin AV, Shors TJ (1998) Hippocampal-dependent trace conditioning is enhanced by stress in males, but impaired by stress in females. Soc Neurosci Abstr 24:267.1.

Woolley CS, McEwen BS (1992) Estradiol mediates fluctuation in hippocampal synapse density during the estrous cycle in the adult rat. J Neurosci 12:2549-2554.

Woolley CS, Gould E, Frankfurt M, McEwen BS (1990) Naturally occurring fluctuation in dendritic spine density on adult hippocampal pyramidal neurons. J Neurosci 10:4035-4039. 